\title{
A COVID-19 E O IMPACTO ECONÔMICO NAS MICRO E PEQUENAS EMPRESAS
}

\section{ARTIGO ORIGINAL}

OLIVEIRA, Caroline Silva de ${ }^{1}$

OLIVEIRA, Caroline Silva de. A COVID-19 e o impacto econômico nas micro e pequenas empresas. Revista Científica Multidisciplinar Núcleo do Conhecimento. Ano 05, Ed. 06, Vol. 10, pp. 39-56. Junho de 2020. ISSN: 2448-0959, Link de acesso: https://www.nucleodoconhecimento.com.br/administracao/impactoeconomico

\section{RESUMO}

Este trabalho tem por objetivo abordar o impacto econômico que a pandemia da COVID - 19 tem causado nas micro e pequenas empresas e bem como os seus efeitos na economia brasileira de forma geral. Para melhor compreensão do tema proposto, serão apresentados assuntos como: a importância dos micros e pequenos negócios para a economia do Brasil, as consequências negativas do Novo Coronavírus na operacionalidade das micro e pequenas organizações e as medidas governamentais para diminuir esses impactos. Com a finalidade de elucidar a aplicabilidade do assunto proposto, esse artigo terá foco nos micros e pequenos negócios como: bares, restaurantes, agências de turismo e comércio em geral. Esta pesquisa é estruturada em referências bibliográficas, utiliza métodos estatísticos e se baseia em informações de instituições renomadas como: Sebrae, Abrasel (Associação Brasileira de Bares e Restaurantes) e FGV. Por meio desses e outros órgãos, pôdese realizar uma análise argumentativa e exploratória, legitimando assim, todos os dados e informações registrados nesse trabalho de pesquisa. Os dados e informações mencionados nesse trabalho são de caráter atual e são baseados entre o período do final do mês de março, quando teve início o surto do Novo Coronavírus no Brasil, e

\footnotetext{
${ }^{1}$ Pós-graduação em Gestão de Pessoas. Graduação em Administração.
} 
meados de Maio. Além dos temas mencionados, serão exploradas medidas e soluções que as empesas, órgãos governamentais e outras instituições adotaram ou propuseram, para driblarem os efeitos da COVID - 19 em suas economias, como o Home Office, a intensificação do método de deliveries e entre outras formas eficazes para esse momento de crise.

Palavras chaves: COVID - 19, micros e pequenas empresas, economia, medidas governamentais.

\section{INTRODUÇÃO}

O surto do Novo Coronavírus (COVID - 19) já alcançou cerca de 200 países, vitimando mais de 100 mil pessoas. No Brasil, até o momento, já são 747.561 casos confirmados e 38.701 mortes.

Como forma de desacelerar o contágio e seguindo as orientações do Ministério da saúde e as determinações dos governos federais, estaduais e municipais, foi determinado o isolamento social.

A pandemia da COVID -19 e consequentemente o isolamento social, por sua vez, impuseram à sociedade medidas drásticas e com isso afetaram, negativamente, principalmente as micro e pequenas empresas em todo o Brasil.

Segundo o Sebrae (2020), na terceira semana de março, quando as medidas de restrições ainda estavam no início, os empresários declararam queda de $64 \%$ no faturamento. Com base nas características da crise e analisando o que ocorreu em países como China, Coreia do sul, Itália e Irã, que tiveram uma explosão de casos antes do Brasil, é possível considerar que alguns segmentos devem ser especialmente afetados.

Nestes setores, existem mais de 13 milhões de pequenos negócios que empregam 21,5 milhões de pessoas e uma folha salarial de mais de $R \$ 611$ bilhões anuais. Abaixo serão apresentadas as 15 atividades econômicas que mais concentram micros e pequenos negócios. 
Figura 1 - Distribuição dos pequenos negócios nas atividades mais vulneráveis à crise do COVID-19 por UF.

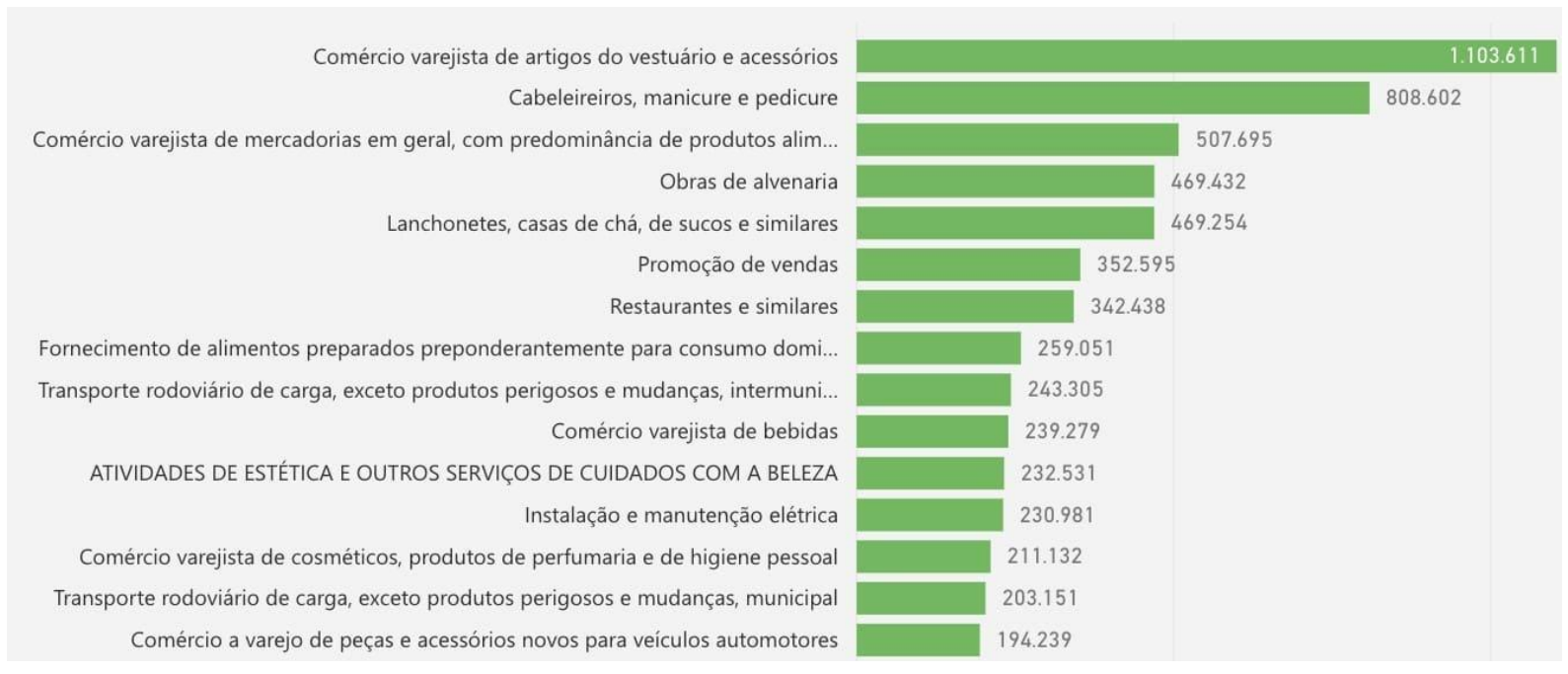

Fonte: Sebrae, com base em dados da Receita Federal, 2020.

O Brasil, atualmente, contabiliza 15 milhões de pequenas empresas, que representam cerca de $30 \%$ do Produto Interno Bruto Nacional. Diante dessa crise muitas empresas optaram por demissões em massa, reduzindo assim o custo com folha de pagamentos. Somente no setor de restaurantes a Associação Nacional estima que podem ocorrer entre 600 a 800 mil demissões no país. Já a Associação Brasileira das Lojas Satélites (Ablos), que reúne as lojas menores dos Shoppings e a Associação Brasileira de Bares e Restaurantes (Abrasel), projetam cerca de 5 milhões de desempregados até o fim de Abril.

O advento da pandemia do Novo Coronavírus tem causado uma desestruturação na economia mundial, pois muitas empresas, lojas e comércios tiveram que encerrar momentaneamente suas operações e outros tiveram que atuar de forma limitada.

A economia é uma ciência e uma engrenagem de suma importância para o funcionamento e uma boa dinâmica da sociedade. As micro e pequenas empresas têm uma parcela significativa no movimento da economia brasileira, pois gera empregabilidade, tem ótima participação no mercado e aumenta as exportações nacionais. 
Em face dessa crise, os governos e instituições privadas tiveram que adotar algumas medidas para minimizar o impacto econômico que essa pandemia vem causando nos micros e pequenos negócios brasileiros.

Algumas das medidas implementadas pelo governo federal foram: facilitar as operações de crédito para micros e pequenas empresas, suspensão no recolhimento do FGTS, linha de crédito para folha de pagamento e entre outras.

\section{A IMPORTÂNCIA DAS MICRO E PEQUENAS EMPRESAS PARA A ECONOMIA BRASILEIRA}

Existe um mito de que somente as grandes organizações e multinacionais movimentam a economia, porém os micros e pequenos negócios desempenham um papel importante no desenvolvimento e crescimento econômico do país. Segundo o IBGE (2014), esses setores são responsáveis por quase 60\% dos quase 100 milhões de empregos no país.

Atualmente, um terço da riqueza nacional é proveniente dos micros e pequenos negócios. De acordo com o Sebrae (2014), os Micros e Pequenos negócios já são os principais geradores de riqueza no comércio brasileiro (53,4\% do PIB deste setor). Já no PIB do setor industrial, a participação das micro e pequenas empresas $(22,5 \%)$ já se aproximam dos médios negócios (24,5\%). E no setor de serviços, mais de um terço do PIB nacional $(36,3 \%)$ provem das pequenas empresas.

Esses dados confirmam a importância das Micro e pequenas empresas no desenvolvimento socioeconômico do país. As MPEs vêm adquirindo, ao longo de 30 anos, uma relevância crescente no país. As informações a seguir ratificam tal afirmativa em variadas dimensões da realidade nacional:

- As Micro e pequenas empresas geraram, em 2011, 27\% do valor adicionado do conjunto de atividades como: comércio, serviços e indústria;

- Esse índice tem aumentado na série histórica, iniciada em 1985, quando esse indicador representava de $21,0 \%$ do valor adicionado (PIB), e em 2001, 23,2\%; 
- Serviços e comércio representaram, em 2011, $19 \%$ do valor adicionado, enquanto a indústria totalizava $7,8 \%$;

- Em relação ao número de empresas, as MPEs representaram, em 2011, nas atividades de serviços e de comércio, respectivamente, $98 \%$ e $99 \%$ do total de empresas formalizadas;

- Em relação ao emprego, as MPEs representavam $44 \%$ dos empregos formais em serviços, e aproximadamente $70 \%$ dos empregos gerados no comércio;

- Cerca de 50\% das remunerações do setor formal do comércio foram pagas, em 2011, por MPE.

Não somente contribuem para geração de riquezas para a nação, como também têm uma excelente parcela no mercado, gerando dessa forma muitos empregos. Esses micros e pequenos negócios têm uma capacidade enorme de gerar renda para a sociedade. Segundo o Sebrae (2018), no período de 2006 a 2016, a participação desse ramo de negócios no estoque de empregos no país cresceu de 53,5\% para $54,5 \%$.

Em dez anos, houve um aumento de 1,1 milhão de micros e pequenos negócios no Brasil, o que significa evolução de $21,9 \%$ no número de negócios responsáveis pela geração de mais de 5 milhões de novos empregos. No período de 2017, as MPEs geraram cerca de 47,4 mil novos postos de empregos contra apenas 12,5 mil das médias e grandes companhias.

Os primeiros sinais de recuperação da economia brasileira foram observados a partir dos resultados positivos da criação de postos de trabalho pelas companhias de pequeno porte.

Com o aumento de pessoas empregadas, aumenta também a renda real agregada. Entre 2006 e 2016, conforme pesquisas realizadas pelo Sebrae (2018), a remuneração média real dos trabalhadores lotados nas pequenas empresas apresentou um aumento de $25,3 \%$, enquanto a dos colaboradores das grandes e médias organizações subiu 14,3\%. Grande parte desses empregados está no setor 
de serviços, que agrupava em 2006, 34,4\% das micro e pequenas empresas. Esse percentual sofreu uma elevação e foi para 41,7\% em 2016.

Além das contribuições citadas acima, as MPEs interferem no aumento do crédito e das exportações brasileiras. As micro e pequenas companhias têm um papel significativo na alavancagem da economia, pois movimenta o setor de créditos e empréstimos bancários.

De acordo com a Exame (2017), no ano de 2011, as MPEs representavam 32,8\% do total de empresas exportadoras. Já no ano de 2016, subiu para 38\%, quando mais de 8 mil empresas de micro e pequeno porte venderam para o exterior.

Em 2016, as MPEs faturaram US\$ 997,7 milhões em vendas para o exterior, o que significou um aumento de $6 \%$ em relação ao ano de 2015 . No mesmo período, o valor exportado pelas grandes e médias empresas caiu 3,5\%.

\section{OS PRINCIPAIS RAMOS DOS MICRO E PEQUENOS NEGÓCIOS AFETADOS PELA COVID-19}

De acordo com recentes pesquisas realizadas pelo Sebrae (2020) com mais de 6 mil empresários e em mercados, já é possível observar alguns efeitos negativos da pandemia do Novo Coronavírus na economia brasileira. Essa mesma pesquisa aponta 14 segmentos que estão sendo afetados negativamente com essa crise. Comércio varejista, turismo e alimentação são os principais setores impactados.

Quadro 1 - Principais setores da economia brasileira impactados pela COVID - 19

\begin{tabular}{|l|l|l|l|l|}
\hline Segmento & \multicolumn{2}{l}{$\begin{array}{l}\text { Impacto já observado } \\
\text { no Brasil }\end{array}$} & Cenário e Tendências & $\begin{array}{l}\text { Dicas } \\
\text { alternativas }\end{array}$ \\
\hline $\begin{array}{l}\text { Comércio } \\
\text { varejista }\end{array}$ & $\begin{array}{l}\text { Desde o início do } \\
\text { surto, }\end{array}$ & o varejo do isolamento social & negócio para \\
brasileiro & já & as pessoas começam & o sistema de \\
& apresentou & uma & a estabilizar seus & delivery é \\
\hline
\end{tabular}




\begin{tabular}{|c|c|c|c|}
\hline & $\begin{array}{l}\text { queda de } 27 \% \text { no } \\
\text { faturamento. } \\
\text { Segundo o Sebrae, o } \\
\text { pequeno negócio do } \\
\text { varejo tem sofrido um } \\
\text { pouco mais, tendo } \\
\text { registrado queda de } \\
69 \% \text { com relação a } \\
\text { uma semana normal. }\end{array}$ & $\begin{array}{l}\text { hábitos de consumo, } \\
\text { com alguma } \\
\text { tendência de leve } \\
\text { queda por conta do } \\
\text { aumento do } \\
\text { desemprego } \\
\text { redução da renda. }\end{array}$ & $\begin{array}{l}\text { uma } \\
\text { alternativa } \\
\text { interessante } \\
\text { para o varejo. } \\
\text { Outra solução } \\
\text { são os } \\
\text { vouchers. } \\
\text { Nesta } \\
\text { alternativa, o } \\
\text { comércio } \\
\text { realiza uma } \\
\text { venda } \\
\text { antecipada e } \\
\text { disponibiliza } \\
\text { um crédito } \\
\text { para } \\
\text { aquisição de } \\
\text { produtos. }\end{array}$ \\
\hline $\begin{array}{l}\text { Alimentos } \mathrm{e} \\
\text { bebidas }\end{array}$ & $\begin{array}{l}\text { Queda de } 66 \% \text { das } \\
\text { vendas na primeira } \\
\text { semana das } \\
\text { restrições sociais. }\end{array}$ & $\begin{array}{l}\text { O segmento de } \\
\text { alimentos e bebidas } \\
\text { foi um dos primeiros } \\
\text { afetados pelas } \\
\text { medidas de restrições } \\
\text { de funcionamento } \\
\text { determinadas pelo } \\
\text { governo. A tendência } \\
\text { é que os } \\
\text { estabelecimentos } \\
\text { que servem refeições } \\
\text { continuem operando } \\
\text { com delivery }\end{array}$ & $\begin{array}{l}\text { Reposicionar } \\
\text { seu negócio: } \\
\text { avaliar qual é } \\
\text { seu maior } \\
\text { diferencial } \\
\text { competitivo e } \\
\text { planejar o seu } \\
\text { modelo de } \\
\text { atuação no } \\
\text { pós-crise. }\end{array}$ \\
\hline
\end{tabular}




\begin{tabular}{|c|c|c|c|}
\hline & & $\begin{array}{l}\text { (entrega) ou Take-out } \\
\text { (retirada). }\end{array}$ & \\
\hline Turismo & $\begin{array}{l}\text { Queda no } \\
\text { faturamento dos } \\
\text { pequenos negócios } \\
\text { de 87\% com relação a } \\
\text { uma semana normal . }\end{array}$ & $\begin{array}{l}\text { O cenário atual } \\
\text { sinaliza para os } \\
\text { negócios do turismo } \\
\text { que a retomada não } \\
\text { tem data prevista. } \\
\text { Mesmo que estados } \\
\text { menores tomem } \\
\text { medidas de } \\
\text { relaxamento } \\
\text { medidas } \\
\text { isolamento há uma } \\
\text { tendência em que a } \\
\text { economia do turismo } \\
\text { ainda seguirá sendo a } \\
\text { mais impactada com } \\
\text { a crise. }\end{array}$ & $\begin{array}{l}\text { Os hotéis } \\
\text { podem } \\
\text { negociar com } \\
\text { governos } \\
\text { estaduais e } \\
\text { municipais } \\
\text { para } \\
\text { hospedar } \\
\text { idosos ou } \\
\text { profissionais } \\
\text { da área de } \\
\text { saúde que } \\
\text { precisam se } \\
\text { manter } \\
\text { isolados de } \\
\text { suas famílias. }\end{array}$ \\
\hline
\end{tabular}

Fonte: adaptada do Sebrae, 2020.

\section{SETOR - COMÉRCIO VAREJISTA}

A importância do mercado varejista no cenário econômico brasileiro vem sendo cada vez mais reconhecida e sido posta em evidência. Além de gerar o maior número de empregos formais no país, o segmento exibe especialmente números expressivos de crescimento e consistentes indicadores de modernização.

Desde o início da pandemia da COVID-19, o varejo brasileiro teve uma queda de 29,0\%, com uma desaceleração no ritmo de queda nas primeiras semanas de Abril. Um levantamento da Fecomércio-RJ (2020) mostra que nos últimos sete dias de enfrentamento à Covid -19, empresários do comércio de bens e serviços do estado do Rio de Janeiro observaram uma queda de $50 \%$ na demanda. 
Outra pesquisa realizada pela Fecomércio-RJ (2020), estima que 335 mil trabalhadores foram ou serão demitidos, enquanto $16,1 \%$ dos entrevistados disseram que o isolamento resultou em perdas de colaboradores. Outros 19\% pensam em dispensar os seus funcionários.

Ainda de acordo com a Instituição, cerca de 83,3\% dos empresários vão passar por dificuldades e a falta de demanda deve atingir $70 \%$. A previsão é de que o PIB do comércio e serviços do estado do Rio de Janeiro sofra uma queda de cerca de $R \$ 30$ bilhões.

A Associação Brasileira de Shopping Centers (Abrasce) (2020) alega que 550 shoppings no Brasil estão sendo impactados pela Covid-19. Esse dado representa cerca de $95 \%$ dos shoppings brasileiros.

Sudeste é a região com maior concentração de Shoppings e consequentemente a mais impactada. Só no estado de São Paulo são 182 shoppings, segundo a ABRASCE (2020), 93 deles somente na capital. Já no Rio de Janeiro, foram 66 shoppings centers afetados pela covid- 19 .

A segunda região mais impactada é a Sul, com cerca de 96 shoppings sob decretos que afetam as atividades de comércio. Logo em seguida vem a região Nordeste, com 93 estabelecimentos com operações suspensas.

Mesmo antes das medidas de restrições sociais impostas pelo governo, o movimento nos shoppings já vinha caindo em torno de $25 \%$ entre os dias 14 e 15 de março, segundo informou a Exame (2020).

Com as restrições, atualmente, mais rígidas, franqueados e lojistas estão encontrando dificuldades em pagar aluguéis e salários. O presidente da Ablos (Associação Brasileira dos Lojistas Satélites) (2020) estima que $80 \%$ dos pequenos lojistas em shoppings não sobreviverão financeiramente a essa crise. Entidades estimam que os cortes no comércio possam gerar 5 milhões de demissões até o fim de abril. 
Segundo a Confederação Nacional do Comércio de Bens, Serviços e Turismo (CNC) (2020), o Índice de Confiança do Empresário do Comércio (ICEC) do período de março mostra que os efeitos da pandemia da Covid-19 começaram a serem sentidos pelo setor. O índice chegou a marca de 128,4 pontos, maior patamar desde dezembro de 2012 (129 pontos).

Os dados dessa pesquisa foram coletados entre o mês de fevereiro e março, uma semana antes das medidas mais drásticas serem tomadas. A queda do ICEC no período de fevereiro e março é explicada, principalmente, por uma retração no índice de expectativas da economia brasileira.

\section{SETOR - ALIMENTOS E BEBIDAS}

Para o setor de bebidas e alimentos, o foco será nos micros e pequenos estabelecimentos de bares e restaurantes brasileiros. Este segmento é um dos mais afetados pela restrição de circulação de pessoas.

Segundo estudo da Associação Nacional de restaurantes (2020), o segmento já demitiu cerca de 1 milhão de empregados no país. A Instituição afirma que representa mais de 9 mil pontos comerciais no país e faturava cerca de $R \$ 400,00$ bilhões anualmente até 2019.

A entidade realizou pesquisas com proprietários de restaurantes entre os dias 9 e 15 de abril e esse novo levantamento apontou que houve um aumento na quantidade de estabelecimentos que precisou dispensar seus colaboradores em função da pandemia do Novo Coronavírus. Agora mais de $76 \%$ dos entrevistados alegaram que já enxugaram o quadro de funcionários. Até o final de março, o número de bares e restaurantes que tinham demitidos era de $62 \%$.

Mesmo com $65 \%$ das empresas atuando com delivery, drive-thru ou entregas na porta, elas tiveram queda de faturamento, superior a $70 \%$ em março em relação à segunda e a primeira quinzena do mês. $18 \%$ tiveram quedas entre 31 e $50 \%$. 
A respeito da manutenção dos negócios no período pós-pandemia, 22\% disseram que fecharão seus estabelecimentos. Já $78 \%$ dos empreendedores alegaram que as operações dos seus negócios continuarão.

Um levantamento realizado pelo Sindicato de Bares e Restaurantes (SindRio) (2020), alega que quase $50 \%$ dos estabelecimentos de bares e restaurantes da cidade carioca está de portas fechadas. A pesquisa, divulgada em 23 de abril de 2020, mostra que $46,6 \%$ dos estabelecimentos não estão operando.

Dos 46,6\%, 10\% encerraram suas operações em definitivo, enxugando 20 mil postos de trabalho. Os dados também mostram que $62 \%$ dos restaurantes tiveram pedidos de crédito negados e que $82 \%$ dos empresários não tiveram acesso às linhas de crédito disponibilizadas.

\section{SETOR - TURISMO}

Apesar das boas perspectivas para o turismo no início deste ano, com expectativa de crescimento em diversas atividades, a interrupção praticamente total de suas operações na segunda quinzena de março do ano de 2020, mudou por completo o futuro desse setor essencial à economia brasileira.

O segmento do turismo tem sido afetado frontalmente pela impossibilidade de viagens, reservas e visitações. Já na primeira quinzena de março, o faturamento do setor de turismo brasileiro caiu 16,7\% em relação ao mesmo período do ano de 2019 , o que representa uma perda equivalente a $\mathrm{R} \$ 2,2$ bilhões.

A riqueza produzida por esse setor contribui para $10,4 \%$ do PIB mundial e gera um em cada dez empregos. É responsável por $20 \%$ da criação de novos postos de trabalho.

No Brasil, todo o segmento emprega cerca de 3 milhões de pessoas e faturou em 2019 , cerca de $R \$ 238,6$ bilhões, segundo o Ministério de Turismo. Logo no início das restrições sociais, as associações afirmaram que $80 \%$ dos hotéis, resorts, parques e atrações turísticas estavam fechados. 
Dados do IBGE (2020) indicam que o turismo no Brasil contribui, diretamente, para cerca de $3,7 \%$ do PIB nacional. No âmbito internacional, o Brasil evoluiu de um patamar de 4,1 milhões de chegadas internacionais de turistas em 2003, para um resultado superior a 6 milhões nos últimos anos.

Em consequência do surto do Coronavírus e mediante as medidas de restrições adotadas pelos governos municipais, estaduais e federais, o setor de turismo está deixando de injetar na economia brasileira cerca de $\mathrm{R} \$ 31,3$ bilhões.

\subsection{CENÁRIO ECONÔMICO}

As restrições tiveram início na segunda quinzena de março e segue até o presente momento para quase todos os estados brasileiros, funcionando apenas os serviços essenciais. Dessa maneira, o status econômico do segmento turístico é de quase paralisação das atividades.

Segundo a FGV (2020), este cenário deve permanecer durante todo o mês de maio (totalizando praticamente 3 meses) quando, de forma geral, poderá ser possível recomeçar a se buscar o reequilíbrio dos negócios, passando por um momento de considerado de estabilização por aproximadamente 12 meses, seguido de uma recuperação econômica do setor de forma a "zerar" a perda causada pelo cenário atual.

Conforme pesquisas realizadas pela FGV (2020), a reação do segmento de Turismo tende a ser lenta, e será incentivada, em um primeiro momento, pelo retorno do consumo, especialmente por viagens essenciais, saúde e visita a parentes após o surto da doença.

Em um segundo momento, será motivada pela retomada das viagens domésticas, de lazer e trabalho. O terceiro e último estágio trará de volta eventos corporativos e culturais e, mais para o fim do momento de estabilização, o início da retomada do turismo internacional. 
Ocorrerá uma elevada redução do volume de produção de atividades turísticas no Brasil devido à pandemia da COVID-19, chegando, em média, a $11 \%$ da produção mensal "normal" (tendo como base a produção dessas atividades no período de 2019) no período do isolamento social.

As perdas econômicas desse setor, em relação ao PIB do segmento em 2019, serão totalmente relevantes. Conforme o volume de produção das atividades, o PIB do setor será de $\mathrm{R} \$ 165,5$ bilhões em 2020 (redução de 38,9\% em comparação ao ano de 2019) e $\mathrm{R} \$ 259,4$ bilhões em 2021 (perto de retomar o patamar de 2019, porém ainda $4,2 \%$ menor). Dessa maneira, a perda total do setor turístico brasileiro será de $R \$$ 116,7 bilhões no biênio 2020-2021 (que representa perda de 21,5\% na produção total do período).

Por fim, para recuperar essa perda, será preciso que o segmento turístico cresça 16,95\% ao ano em 2022 e 2023 - recuperando a perda econômica causada pela pandemia do Novo Coronavírus. No período de estabilização, as atividades do turismo, por meio de várias estratégias e retorno da demanda, poderão retornar ao patamar de 2019. Essa recuperação perfaria aproximadamente $R \$ 303$ bilhões em 2022 e R $\$ 355$ bilhões em 2023 no PIB do segmento.

\section{MEDIDAS GOVERNAMENTAIS E DE INSTITUIÇÕES BANCÁRIAS}

As medidas do governo federal visam reduzir o impacto do Novo Coronavírus na economia das micro e pequenas empresas, resguardar empregos e garantir o pagamento dos salários.

A primeira refere-se ao adiantamento do recolhimento do imposto do Simples Nacional, pelo período de três meses, o que representa a uma renúncia temporária de $\mathrm{R} \$ 22,2$ bilhões da União.

A expectativa é que essa medida beneficie aproximadamente, 4,9 milhões de negócios brasileiros, que são optantes do regime tributário. $O$ pagamento da taxa tributária será adiado para o segundo semestre do ano de 2020. 
A segunda medida será a liberação de $R \$ 5$ bilhões através do Programa de Geração de Renda (Proger), mantido com recursos do Fundo de Amparo do Trabalhador (FAT). O governo irá repassar a quantia para as instituições bancárias públicas para que elas concedam empréstimos direcionados ao capital de giro das micro e pequenas empresas.

No dia 20 de Abril de 2020, A Caixa Econômica Federal e o Serviço Brasileiro de Apoio às Micro e Pequenas Empresas (Sebrae) anunciaram uma linha de crédito no valor de $R \$ 7,5$ bilhões destinada a micro e pequenas empresas e aos microempreendedores individuais (MEls).

A Caixa Econômica Federal diminuiu os juros de até 45\% nas linhas de capital de giro, com taxas a partir de $0,57 \%$ ao mês. Além disso, nas operações parceladas de capital de giro e renegociação há uma carência de até 60 dias.

O BNDES também apresentou algumas medidas para minimizar os efeitos da COVID -19 na economia dos micros e pequenos negócios brasileiros. No dia 22 de março de 2020, o presidente Gustavo Montezano anunciou um primeiro conjunto de medidas, de caráter transversal, envolvendo a preocupação com a sustentação da liquidez e solvência das empresas, o direcionamento de recursos para as micro, pequenas e médias empresas (MPME) - que tendem a ser mais afetadas pela crise - montante de mais ou menos $\mathrm{R} \$ 55$ bilhões.

Houve também um aumento da oferta de crédito para as MPMEs em um total de R $\$$ 5 bilhões. Os empréstimos nessa modalidade terão 24 meses de carência e prazo total de 60 meses, com um limite por cliente de $R \$ 70$ milhões.

Uma característica importante desses financiamentos é que as empresas não precisam especificar a destinação dos recursos, ou seja, o crédito pode ser empregado para capital de giro, tão necessário para a sobrevivência dessas empresas, que são importantes geradoras de empregos.

Segundo o Secretário de Produtividade, Emprego e Competitividade (Sepec) do Ministério da Economia (2020), Carlos da Costa, o governo está priorizando os micros 
e pequenos negócios, pois eles têm mais dificuldades em obter capital de giro e acessar linhas de crédito.

Além disso, o Conselho Monetário Nacional (CMN) aprovou medidas para facilitar a negociação de dívidas bancárias ao dispensar as instituições bancárias de aumentarem o provisionamento, caso essa repactuação ocorra nos próximos seis meses.

Isso alastra a capacidade de utilização de capital de bancos com a finalidade de terem melhores condições de realizar as eventuais renegociações e de manter o fluxo de concessão de crédito, baixando a necessidade de capital próprio para a alavancagem das operações. Dessa forma existirá a possibilidade de aumentar a capacidade de concessão de crédito em torno de $\mathrm{R} \$ 637$ bilhões.

\section{ANÁLISE DA EFICÁCIA DAS MEDIDAS}

Com o surto do Novo Coronavírus no Brasil, a busca por empréstimos cresceu bastante, porém o crédito bancário segue restrito e caro. De acordo com uma pesquisa realizada pelo Sebrae (2020), 60\% dos pequenos negócios que recorreram a empréstimos tiveram seu pedido negado.

As medidas anunciadas pelo governo federal e Banco Central não têm sido tão eficientes, pois as linhas de crédito estão com taxas de juros muito altas. Isso está ocorrendo porque as instituições bancárias têm receio do aumento do índice de inadimplência.

Segundo levantamento da Associação Nacional dos Executivos de Finanças Administração e Contabilidade (Anefac) (2020), as taxas de juros das operações de crédito tiveram um aumento em março. A taxa de juros para pessoas jurídicas oscilou de $3,12 \%$ ao mês em fevereiro para $3,17 \%$ em março.

Já na linha emergencial para financiar salários dos trabalhadores, na qual o Tesouro Nacional arcará com $85 \%$ dos $\mathrm{R} \$ 40$ bilhões ofertados, os juros são de $3,75 \%$ ao ano. 
Segundo o diretor executivo da Anefac (2020), Miguel José Ribeiro de Oliveira, mesmo com a queda da taxa Selic, atualmente em 3,75\% e com as medidas do Banco Central para aumentar a liquidez, as taxas impostas pelas instituições bancárias nas variadas linhas seguem com tendências de alta.

De acordo com a FGV (2020), o conjunto de ações anunciadas pelo governo já equivalem a $7,8 \%$ do PIB, sendo que desse percentual $2,1 \%$ se referem a medidas de crédito, índice bem baixo em comparação com outros países.

Por essas razões, as ações nas linhas de crédito continuam aquém do que é necessário para que os micros e pequenos negócios não "quebrem" financeiramente.

Segundo o Economista Manoel Pires, coordenador do Observatório de Política Fiscal da FGV (2020), o que falta no sistema financeiro não é a liquidez, mas sim maior participação do governo para diminuir o risco e garantir maior facilidade no acesso ao crédito.

É necessário que o Governo Federal ofereça recursos do Tesouro para os bancos públicos atuarem de maneira mais arrojada ou criar fundos garantidores com recursos do Tesouro para dar segurança para os bancos comerciais operarem.

Outra maneira para solucionar o problema é o Banco Central atuar comprando carteiras de crédito assim como o Fed (Federal Reserve, o Banco Central dos EUA) faz.

\section{CONSIDERAÇÕES FINAIS}

Em suma, o advento da pandemia do Novo Coronavírus (Covid-19) tem causado efeitos catastróficos na saúde econômica das micro e pequenas empresas brasileiras. Muitos negócios tiveram suas operações encerradas temporariamente, enquanto outros encerraram por definitivo. Gerando assim demissões e queda brusca no faturamento. 
É inegável a importância e relevância da participação das micros e pequenas empresas na economia brasileira, pois esses milhares de negócios é uma fonte rica de geração de empregos e renda para a sociedade. Contribuindo de forma significativa para construção da riqueza nacional (PIB).

Para minimizar os efeitos dessa doença, o governo federal anunciou algumas medidas fiscais e econômicas. Porém como foram observados, os resultados não têm se mostrado eficazes. É fundamental que o governo tenha uma participação mais ativa e incisiva.

\section{REFERÊNCIAS}

AGÊNCIA BNDES DE NOTÍCIAS. O BNDES e as medidas econômicas brasileiras $\begin{array}{lllllll}\text { contra } & 0 & \text { Covid } & - & 19 . & \text { Disponível }\end{array}$ https://agenciadenoticias.bndes.gov.br/detalhe/blogdesenvolvimento/O-BNDES-e-asmedidas-economicas-brasileiras-contra-o-Covid-19/. Acesso em: 24. abr. 2020.

AGÊNCIA BRASIL. Efeitos do coronavírus começam a ser sentidos pelo comércio, diz CNC.

Disponível em: https://agenciabrasil.ebc.com.br/economia/noticia/2020-03/efeitos-docoronavirus-comecam-ser-sentidos-pelo-comercio-diz-cnc. Acesso em: 08. abr. 2020.

AGÊNCIA BRASIL. Covid-19 provoca perdas de $\mathbf{R} \$ \mathbf{2 , 2}$ bi no turismo brasileiro, diz CNC. Disponível em: https://agenciabrasil.ebc.com.br/economia/noticia/202003/covid-19-provoca-perdas-de-r-22-bi-no-turismo-brasileiro-diz-cnc. Acesso em: 06. mai. 2020.

AGÊNCIA SEBRAE DE NOTÍCIAS. Pesquisa mostra a importância da MPE para manutenção dos empregos no Brasil. Disponível em: http://www.agenciasebrae.com.br/sites/asn/uf/NA/pesquisa-mostra-a-importancia-dampe-para-manutencao-dos-empregos-no- 
brasil,4239123c73ea4610VgnVCM1000004c00210aRCRD. Acesso em: 16. abr. 2020.

ANR. Nova pesquisa ANR aponta que mais de $76 \%$ dos estabelecimentos já demitiram na crise. Disponível em: https://anrbrasil.org.br/nova-pesquisa-anraponta-que-mais-de-76-dos-estabelecimentos-ja-demitiram-na-crise/. Acesso em: 20. abr. 2020.

ANR. Quase metade dos bares e restaurantes do Rio de Janeiro está fechada , segundo SindRio. Disponível em: https://anrbrasil.org.br/quase-metade-dos-barese-restaurantes-do-rio-de-janeiro-esta-fechada-segundo-sindrio/2020. Acesso em: 22. abr. 2020.

BLOG - EGESTOR. Entenda a importância das micro e pequenas empresas para - Brasil. Disponível em: https://blog.egestor.com.br/entenda-a-importancia-dasmicro-e-pequenas-empresas-para-o-brasil/. Acesso em: 10. abr. 2020.

CET LOGISTICS. Varejo. Disponível em: https://www.cetlogistics.com/segmento/varejo. Acesso em: 17. abr. 2020.

CIELO. Boletim - Impacto do COVID-19 no Varejo Brasileiro. Disponível em: https://static.poder360.com.br/2020/04/varejo-mar-abr-covid-cielo.pdf. Acesso em: 30. abr. 2020.

EXAME. 5 alternativas que as empresas podem adotar antes de pensar em demitir. Disponível em: https://exame.abril.com.br/pme/5-alternativas-que-asempresas-podem-adotar-antes-de-pensar-em-demitir/_Acesso em: 16. abr. 2020.

EXAME. 95\% dos shoppings no Brasil foram afetados por coronavírus, diz associação. Disponível em: https://exame.abril.com.br/negocios/95-dos-shoppingsbrasileiros-foram-afetados-por-coronavirus-diz-associacao/__Acesso em: 15. abr. 2020. 
EXAME. Micro e pequenas empresas exportam cada vez mais. Disponível em: https://exame.abril.com.br/pme/cresce-exportacao-nas-micro-e-pequenas-empresas/ Acesso em: 25. abr. 2020.

FECOMÉRCIO RJ. Coronavírus pode causar perda de $\mathbf{R} \$ \mathbf{3 0}$ bi ao PIB do Comércio e Serviços do estado do Rio, aponta IFec Rj. Disponível em: http://www.fecomercio-rj.org.br/noticias/coronavirus-pode-causar-perda-de-r-30-biao-pib-do-comercio-e-servicos-do-estado-do-rio-aponta-ifec. Acesso em: 20. abr. 2020.

FGV. Impacto Econômico do Covid-19: Propostas para o Turismo Brasileiro Abril. 2020.

FOLHA DIRIGIDA. Coronavírus: impacto no comércio faz lojistas pensarem em demissões. em: https://folhadirigida.com.br/empregos/especiais/coronavirus-impacto-no-comerciofaz-lojistas-pensarem-em-demissoes. Acesso em: 10. abr. 2020.

GAZETA WEB. Caixa reduz juros e autoriza pausa no pagamento de dívidas. Disponível em : https:/gazetaweb.globo.com/portal/noticia/2020/03/caixa-reduzjuros-e-autoriza-pausa-no-pagamento-de-dividas_100369.php. Acesso em: 30. Abr. 2020.

GLOBO.COM. Com pandemia, busca por empréstimos cresce, mas crédito bancário segue restrito e caro. Disponível em: https://g1.globo.com/economia/noticia/2020/04/16/com-pandemia-busca-poremprestimos-cresce-mas-credito-bancario-segue-restrito-e-caro.ghtml. Acesso em: 07. mai. 2020.

GOVERNO DO BRASIL. Boletim das medidas tomadas em função da Covid-19 (Coronavírus). Disponível em: https://www.gov.br/economia/pt-br/centrais-deconteudo/publicacoes/boletins/covid-19/timeline/abril/20-de-abril-de-2020. Acesso em: 05. mai. 2020. 
GOVERNO DO BRASIL. Governo anuncia medidas de ajuda econômica para micro e pequenas empresas. Disponível em: https://www.gov.br/ptbr/noticias/financas-impostos-e-gestao-publica/2020/03/governo-anuncia-medidasde-ajuda-economica-para-micro-e-pequenas-empresas. Acesso em: 2. mai. 2020.

JORNAL DE BRASÍLIA. O turismo agoniza com o avanço do COVID-19. Disponível em: https://jornaldebrasilia.com.br/blogs-e-colunas/de-passagem/o-turismo-agonizacom-o-avanco-do-covid-19/. Acesso em: 20. abr. 2020.

MARCUS MARQUES. A Importância dos Pequenos Negócios Para a Geração de Empregos no Brasil. Disponível em: http://marcusmarques.com.br/pequenas-emedias-empresas/importancia-pequenos-negocios-para-a-geracao-empregos-nobrasil/. Acesso em: 9. abr. 2020.

O GLOBO. Brasil tem 38701 mortes confirmadas por covid-19 aponta consórcio de veículos de imprensa em boletim das 13h. Disponível em: https://oglobo.globo.com/sociedade/brasil-tem-38701-mortes-confirmadas-por-covid19-aponta-consorcio-de-veiculos-de-imprensa-em-boletim-das-13h-24472468. Acesso em: 10. jun. 2020.

O TEMPO. Coronavírus: pesquisa mostra impacto do isolamento no mercado de trabalho no Rio. Disponível em: https://www.otempo.com.br/coronavirus/coronaviruspesquisa-mostra-impacto-do-isolamento-no-mercado-de-trabalho-no-rio-1.2329001. Acesso em: 27. abr. 2020.

REVISTA PEGN. Pesquisa mostra a importância da MPE para manutenção dos empregos no Brasil. Disponível em: https://revistapegn.globo.com/Negocios/noticia/2018/07/pesquisa-mostraimportancia-da-mpe-para-manutencao-dos-empregos-no-brasil.html. Acesso em: 9. abr. 2020.

SEBRAE. Conheça as medidas do governo para diminuir o impacto do coronavírus. Disponível em: https://m.sebrae.com.br/sites/PortalSebrae/artigos/conheca-as-medidas-do-governo- 
para-diminuir-o-impacto-do-

coronavirus,eec7013d92e01710VgnVCM1000004c00210aRCRD. Acesso em: 30. abril. 2020.

SEBRAE. Impactos e tendências da COVID - 19 nos pequenos negócios - edição 3. 2020

SEBRAE. Anuário do Trabalho nos Pequenos Negócios - 2016. 2018.

SEBRAE. Participação das Micro e Pequenas Empresas na Economia Brasileira. 2014.

Enviado: Maio, 2020.

Aprovado: Junho, 2020. 